\title{
An Accelerated Rural Training Program
}

\author{
James H. Stageman, MD, Robert C. Bowman, MD, and Jeffrey D. Harrison, MD
}

Background: Several authors have pointed out the need for enhanced training for those residents contemplating rural practices. Most students and policy makers are reluctant to commit to primary care training beyond the required 3 years.

Methods: The University of Nebraska Medical Center received approval for an accelerated family practice training program in 1993, and developed a 4-year program that requires a 1-year rural procedures fellowship and a commitment to practice in rural Nebraska.

Results: The Nebraska accelerated rural training program has recruited 10 classes to this program and has placed more than $50 \%$ of the graduates in communities with a population of less than 8,000 .

Conclusion: The requirements of this program are unique. Special consideration must address the issues of recruitment of students, integration into the basic program, licensure issues, determination of fellowship training needs, and faculty recruitment. (J Am Board Fam Pract 2003;16:124-30.)

Counties without a critical mass of at least 4 physicians face formidable challenges when attempting to maintain their rural health systems. ${ }^{1}$ They often have difficulty generating enough volume to maintain facilities and a sufficient number of physicians to share the call load. Nebraska ranks second in the nation with 47 of these counties.

Norris et $\mathrm{al}^{2}$ detailed some of the perceived impediments to attracting physicians to and retaining them in rural communities. In particular, there was a perception among potential candidates that their 3 years of residency training were not adequate to prepare them for the uncertainties of rural practice. ${ }^{3}$ Another concern was the perception that rural physicians were not reimbursed as well as were their urban counterparts and, as a result, recent graduates would have more difficulty paying off their ever-increasing student loans. ${ }^{4}$

The College of Medicine at the University of Nebraska Medical Center (UNMC) has a history of developing numerous initiatives to help address the problem of physician shortages in rural Nebraska. The Department of Family Medicine has created four such programs at the graduate level:

1. The combined outstate residency experience (CORE) program, which is a joint program

Submitted, revised 3 June 2002.

From the Department of Family Medicine (JHS, RCB, JDH), University of Nebraska Medical Center, Omaha. Address reprint requests to James H. Stageman, MD, Department of Family Medicine - UNMC, 983075 Nebraska Medical Center, Omaha, NE 68198-3075. established in 1982 between the Department of Family Medicine and its affiliate program in Lincoln, Neb, and requires all residents to spend 2 months during either their second or third postgraduate years (PGY 2 or 3) in rural Nebraska. Four rural sites are selected for up to 3 years based on need for physicians and willingness to train residents. By having a constant stream of residents for a 3 -year period, communities have been able to continue to maintain services and facilities.

2. The primary care program described below.

3. The University of Nebraska rural training track program, initiated in 1992, which is a separately accredited residency that consists of five rural training track sites spread across the state. Residents in the rural training track programs spend their first year in Omaha and their last 2 years in a rural site (2.1 format), with 2 residents per year level at each site (2-2-2).

4. Our accelerated 3-year medical school, 4-year residency track, the accelerated rural training program, which is the subject of this article and which began in 1993 .

Rural medical educators have long searched for an opportunity to change the usual process of medical education to help meet the needs of rural communities. An opportunity presented itself in 1991, when the American Board of Family Practice $(\mathrm{ABFP})$ issued a request for proposals to replicate the success of the original University of Kentucky accelerated program. UNMC answered with a pro- 
posal that would adapt the 3-year medical school, 3-year residency model into a 3-year medical school, 4-year residency program that would also meet the needs of rural communities.

In designing the 3-year medical school, 4-year residency program, the authors theorized that, as small rural hospitals closed, the surviving hospitals would eventually achieve a critical mass of patients that would allow them to remain viable. The remaining hospitals would need a cadre of 3 to 5 well-trained family physicians who would (1) be comfortable practicing in a small rural community; (2) provide each other with moral support and a reasonable call schedule, thereby addressing one of the lifestyle issues particularly important to today's graduates; (3) have extra training in procedural medicine that would allow them to be more comfortable in managing a higher percentage of their cases in the local hospital, thereby insuring its continued viability; (4) be able to perform additional procedures, which would increase the financial viability of rural practices, including the ability to manage their substantial student loans more effectively; and (5) be comfortable providing consultant services to physician extenders who practice in surrounding communities that are too small to support their own family physician.

\section{Previous Experiences and Program Development}

Concerned about some of the issues later outlined by Norris and colleagues in their needs assessment article, ${ }^{2}$ the Department of Family Medicine had, in the late 1980s, already embarked on a novel program to enhance training for those interested in rural practice. ${ }^{5}$ In a joint venture with the Department of Internal Medicine, the Department of Family Medicine had developed a 4-year primary care track that was to lead participants to becoming board-certified in both family practice and internal medicine. This latter aspect never came to fruition. As it turned out, there was very little interest among students for a 4-year postgraduate training program in primary care. Convinced of the potential value of this type of training, the combined departments decided to move this program up 1 year, thereby making the senior year of medical school a structured subinternship. In effect, a 3-year medical school, 1-year subinternship, 3-year residency program was created.
To address some of the financial concerns of students, the College of Medicine agreed to forego all senior year tuition and fees if a resident completed the 4 years of training. The college also agreed to provide a senior year cost-of-living allowance in return for practicing in rural Nebraska for at least 2 years. With the changes, interest surged, and the program became competitive. It has become a reliable feeder program for the rural training track programs, in that more than one half of the participants have chosen to transfer to a rural training track site for their final 2 years of training.

\section{Methods}

Given our previous experiences with the students in developing the primary care program, yet still wanting to offer 4 years of family practice training to our rural graduates, creating an accelerated track seemed a perfect opportunity to develop our 3-year medical school, 4-year residency (3-4) program or, more accurately, a 3-year medical school, 3-year residency, 1-year fellowship (3-3-1) program. We decided that the fourth year of training would be in the form of a rural fellowship year that would focus on procedural medicine and add depth to the breadth already obtained during the residents' first 3 years of training (Figure 1).

An additional consideration was that, by adding the extra year of training at the PGY-4 level, we believed it would be easier for the teaching faculty to allow the trainee a higher level of participation in their cases. In academic centers, these PGY-4 fellows were truly fellows, with the reputation and license that this designation provided. For nonacademic locations, the fellows were graduates and would be fully experienced and functional. In other words, they were more valuable as colleagues and assistants for the specialty faculty.

Finally, to stimulate interest and decrease student debt load, we decided to provide the same financial benefits in the form of forgivable loans, as described above.

\section{Obstacles}

From the beginning, the greatest challenges in establishing the program were internal. Obstacles were encountered with licensure, acceptance by hospital and clinic personnel, agreements between undergraduate and graduate programs, recruitment of students, recruitment of dedicated specialty fac- 


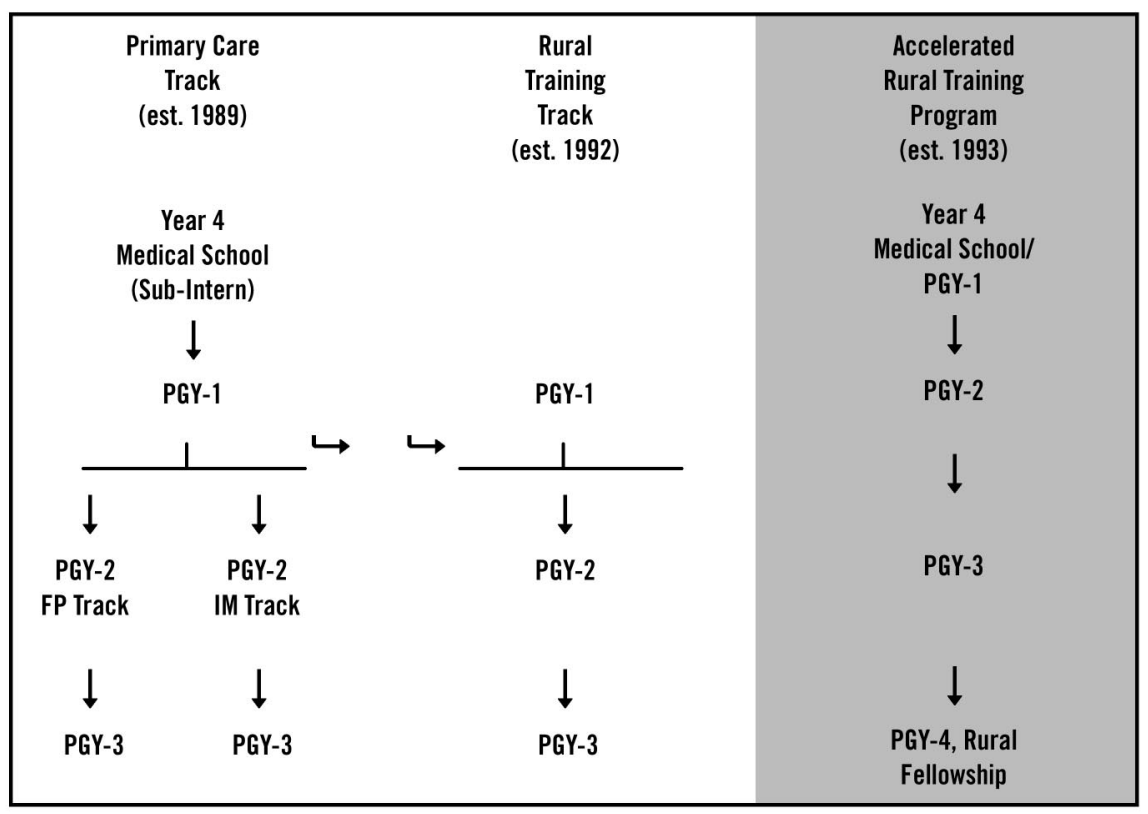

Figure 1. Rural initiatives in primary care at the University of Nebraska Medical Center.

ulty from outside the department, the repercussions of establishing a competing program, and other unique requirements beyond typical graduate education.

\section{Licensure}

Although we initially envisioned that the accelerated residents would fit into our existing residency program, we encountered difficulties. Although the ABFP considers the accelerated residents postgraduate trainees, no one else does. The state of $\mathrm{Ne}$ braska was unable to grant them an educational permit until they officially graduated from medical school. As a result, orders written by first-year accelerated residents could not be taken off the chart, and their prescriptions could not be filled. To circumvent this problem, we moved some PGY-2 outpatient experiences (for which they were not required to sign orders or write prescriptions) to the PGY-1 year. For the remaining PGY-1 inpatient experiences, there was an upper level supervisory family physician resident or faculty member available as a cosigner. Inpatient experiences in which the resident was expected to serve in a supervisory role were moved back until after medical school graduation and early into the PGY-2 year.

\section{Recruitment of Students}

In some ways, the accelerated rural training program has had to compete with the primary care program, as well as the rural training track programs. The family medicine residency in Lincoln also has an excellent record for graduating rural physicians. As the years have passed, all the programs have recruited well and developed individual applicant pools. For some, the Omaha location allows spouses to finish education or training. Others are tired of urban life and move toward ruralbased training.

\section{Practice in Rural Locations}

Previous research has shown that residents tend to locate near their training locations. ${ }^{6}$ Some doubted that our accelerated rural training program graduates would go into rural practice after 7 years of living in Omaha. In addition to the lifestyle expectations, single accelerated residents would be more likely to meet spouses with established urban positions or careers that were unsuitable for rural locations. There were questions whether the early commitment and procedural training provide enough motivation to overcome the urban lifestyle and expectations. Our experience has been that they do.

\section{Recruitment of Specialty Faculty}

The last issue was faculty recruitment for the PGY-4 year, which was critical if the year was going to be successful. Should the program fail to deliver on the promise to provide hands-on proce- 
Table 1. Postgraduate Year 1 Curriculum.

\begin{tabular}{ll}
\hline Unit & \multicolumn{1}{c}{ Comments } \\
$\begin{array}{l}\text { Orientation } \\
\text { Dermatology } \\
\text { Orthopedics } \\
\text { Emergency medicine }\end{array}$ & $\begin{array}{l}\text { Outpatient experience usually appearing later in residency curriculum } \\
\text { Outpatient experience usually appearing later in residency curriculum }\end{array}$ \\
Obstetrics & \\
Obstetrics & \\
Basic science & Senior year requirement, counted as a month of elective for residency accounting purposes \\
Allergy, immunology, otolaryngology & Outpatient experience usually appearing later in residency curriculum \\
Outpatient pediatrics & \\
Urology (1/2 month) & Outpatient experience usually appearing later in residency curriculum \\
Occupational medicine (1/2 month) & Outpatient experience usually appearing later in residency curriculum \\
Inpatient family practice & \\
Inpatient family practice &
\end{tabular}

dural training, the residents would likely leave the program after only 3 years, since they were already eligible to sit for their boards. In this regard, Omaha is somewhat unique in that it is a relatively small community with two medical schools. Because of the number of trainees in the city at both the student and resident levels, we believed it would be difficult to interject this new class of trainees into the existing training system. Instead, we looked outside our traditional training settings for faculty not currently involved in the medical education system. In so doing, we found that some of our best supporters, in both the academic centers and community hospital settings, were physicians who had grown up in rural environments or had family in rural areas and who appreciated the need for well-trained rural family physicians.

\section{Curriculum Design}

As a result of the licensure issues mentioned above, the PGY-1 year was modified as shown in Table 1.

The net result of the above adjustment was that, although their first 18 months were slightly out of sequence from their fellow residents, by the end of that time they were, for all intents and purposes, equal. One serendipitous outcome from adjusting the schedule was that, by intermixing less demanding with more challenging rotations, the internship year (stretched over 18 months) was much less stressful and helped us address the concern expressed by some applicants as to whether they would be ready to begin their residency a year early.
To assist in the development of the PGY-4 year, several faculty physicians with previous rural experience met to address the questions, "What to include in the fellowship?" "What were the types of cases that caused us to become anxious when we were in rural practice." "What did we wish we had more of?" From this list, which is similar to the list obtained by Bergus et al, ${ }^{7}$ we fashioned a PGY-4 year, as shown in Table 2 below.

Because rural physicians are more involved in the day-to-day management of their businesses, we also included 1 day each month of additional practice management, and PGY-4 residents continued to have 1 day of continuity clinic per week in their family practice center.

\section{Results}

We have now recruited 10 classes of accelerated residents (39 physicians), 5 classes have graduated, and the practice plans for the class of 2002 are set. Twenty-nine of the 39 participants (74\%) have

Table 2. Postgraduate Year 4 Curriculum.

\begin{tabular}{ll}
\hline Unit & Duration \\
\hline Obstetrics, gynecology & $3 \mathrm{mo}$ \\
Surgery & $3 \mathrm{mo}$, later shortened to \\
& $2 \mathrm{mo}$ plus an elective \\
Neonatal intensive care unit & $1 \mathrm{mo}$ \\
Intensive care unit & $1 \mathrm{mo}$ \\
Anesthesia & $1 \mathrm{mo}$ \\
Gastroenterology & $6 \mathrm{wk}$ \\
Orthopedics & $6 \mathrm{wk}$ \\
\hline
\end{tabular}


come from rural communities with the remainder from the Omaha-Lincoln area.

One rule that the ABFP established regarding accelerated programs was that accelerated residents could not constitute more than one third of an entering class and, for us, that was 4 students a year. Our first 4 accelerated residents began the program in July 1993. Initially, we found that we were competing for applicants with the primary care program. As the years passed, both programs have remained nearly fully subscribed with high-quality residents and have slowly developed individual applicant pools, although some applicants apply to both programs.

Accelerated residents have had no difficulty in adjusting to residency training, have been wellaccepted by the other members of the residency class, have shown the same levels of leadership as their classmates in the traditional track, and have shown the same amount of academic growth based on standardized testing.

In addition, residents in the accelerated program have developed their own esprit de corps and a vested interest in the success of the program. They see future graduates of the program as their potential future partners.

All graduates have become board-certified by the ABFP. Eighteen of 24 (75\%) have completed all 4 years of training. Six left after completing 3 years. Twenty of $24(83 \%)$ are practicing in Nebraska, and $14(58 \%)$ are practicing in towns with populations of less than 8,000 .

Of those in the latter group, nearly all have gone into practice in state-designated shortage areas, and 8 graduates have gone into practices together (four groups of 2 physicians).

\section{Discussion}

The accelerated rural training program at the UNMC has met expectations. A high percentage of graduates have gone into rural practices, and most graduates have chosen locations that need the most help.

The success of the program is a little surprising, given the long stay in an urban training location. It seems that the combination of rural background, specialized training, and financial incentives has been more than enough to overcome any perceived drawbacks.

A key factor in the success of the program has been the efforts of the medical school admissions office. Since the accelerated rural training program depends on candidates interested in rural practices and competes with other rural-oriented programs, a sufficient number of candidates must be admitted each year for all these programs, approximately 15 per year. To address this issue, the UNMC College of Medicine makes a concerted effort to accept students who have a rural orientation.

There are some educational advantages to the Nebraska program. The accelerated rural training program puts two superb learning years back to back (third year of medical school and first year of postgraduate training). Accelerated residents encounter an increasing gradation of challenges and responsibilities throughout their 7 years of training, thereby avoiding the less challenging fourth year of medical school. The program might also be advantageous for some residents who are interested in rural practice but who might not be as selfdirected as the residents who typically apply to rural training track programs. The fellowship year also facilitates a smoother transition into rural practice, because it allows for more personalized training on the part of the fellows. For example, some fellows have taken surgery and other rotations from specialty physicians with whom they will be working on a regular basis after graduation.

Before the 1960s, there were those who believed that the best physicians needed to go to small towns. ${ }^{8,9}$ In more recent decades, medical education, emphasizing subspecialization, appears to have forgotten those words. The few who have chosen to care for the rural underserved have begun to recognize that the usual forms of medical education are not doing an adequate job of preparing graduates to be comfortable working in a rural environment. Not only do the graduates need to understand the medical aspect of underserved practice, they also experience an often overwhelming constellation of social and community challenges facing such populations. Many believe that mastering medicine, primary care in particular, is a prerequisite to be able to address such concepts as community-oriented primary care, quality of care, practice management, and other areas requiring complex problem-solving beyond patient care.

Accelerated programs can offer some real advantages in specific training for underserved locations. Rabinowitz and others ${ }^{10}$ have noted that rural recruitment is a product of admissions (rural background and family practice interest). Rural reten- 
tion is believed by Pathman ${ }^{11}$ and other rural medical educators to be related to training in medical school and residency. Other than a few rural rotations and the rural training track models, little has been done to explore this area.

One real advantage of an accelerated program might be acceleration of a final decision for rural practice. In a typical family practice residency program, residents do not seriously consider their future practice locations until they have completed their internship year. Residents in the accelerated rural training program make a rural commitment in their third year of medical school. To some degree this is a financial commitment, but even more importantly, it results in structuring their electives, rotations, clinical efforts, and even their personal lives based on a fairly certain decision for practice in rural Nebraska. Such training can help improve retention and practice efficacy in underserved locations. Given that losing a primary care physician from a community results in nearly $\$ 250,000$ in losses and replacement costs, retention must be a high priority. ${ }^{12}$

It should be possible for the accelerated training to extend beyond the graduating residents and into the rural communities. A broader skill set better meets the needs of local patients, helps sustain the local practice and hospital market shares, and improves hospital viability. Health is a major portion of the local economy in the smallest towns, with each physician worth $\$ 350,000$ and 17 jobs in local economic impact.* Additional physicians or fewer gaps between physicians help stabilize the economy, allow communities to retain jobs, and, perhaps, attract new ones. Failure to admit the right students to medical school and train them appropriately is, therefore, a de facto decision to ignore the needs of rural communities.

Given our initial success in rural underserved areas with specific needs, one could also ask whether an accelerated track would be ideal for urban underserved areas as well. More widespread adoption of an accelerated model for rural and inner-city practice preparation would show that family medicine, as a discipline, is clearly interested in service to underserved locations.

*Doeksen GA, Cordes S, Shaffer R. Health care's contribution to rural economic development. Paper prepared for Federal Office of Rural Health, 1992.
Currently, the ABFP continues a moratorium on new accelerated programs. Some have expressed concerns about the potential impact of accelerated programs on the student-residency match. Through the early acceptance process, the typical accelerated program does have a theoretical advantage in the selection of resident applicants. In our program, however, this advantage is neutralized, because we still require 7 years of medical education. The initial success of the program and the potential that such an adaptation might have on the future delivery of health care to the underserved should interest the ABFP.

\section{Summary}

The University of Nebraska has developed a 3-year medical school, 4-year residency (3-4) program that provides extra training for residents wanting to practice in small, rural Nebraska communities. The model appears to be effective in preparing graduates for the rigors of rural practice, and the Department of Family Medicine at the UNMC has had some initial success in facilitating the placement of well-qualified physicians in underserved rural areas of the state. Many questions remain. Does the increased training result in increased job satisfaction, comfort level, and retention? Presumably so, but the passage of time and further evaluation are required before any definitive statements can be made.

In this regard, the Department of Family Medicine has recently completed data collection for a qualitative interview and analysis of the graduates of our rural training track program, which should answer whether this program, following a parallel mission of providing family physicians to rural $\mathrm{Ne}$ braska, is meeting its goals. We plan to complete a similar qualitative analysis of the graduates of the accelerated rural training program to determine whether these graduates are meeting the needs of their rural communities. We then want to compare the experiences of the accelerated rural training program graduates with those of the rural training track graduates and validate the five premises outlined at the beginning of this article.

Although a thorough evaluation of the overall effectiveness of the program is a needed next step, given the initial success of the program, consideration should be given to expanding the model to meet other medical shortage areas. 
Dr. Helen McIlvain and Jenenne Geske provided assistance in the preparation of this manuscript, and Mary Ann Casey, who has spent years facilitating the development and accreditation of our many rural training programs, assisted with final manuscript preparation.

\section{References}

1. Madison DL, Combs CD. Location patterns of recent physician settlers in rural America. J Community Health. 1981;6:267-74.

2. Norris TE, Coombs JB, Carline J. An educational needs assessment of rural family physicians. J Am Board Fam Pract 1996;9:86-93.

3. Norris TE, Acosta DA. A fellowship in rural family medicine: program development and outcomes. Fam Med 1997;29:414-20.

4. Petersdorf RG. Financing medical education. Acad Med 1991;66:61-5.

5. O'Dell DV, Sitorius MA. A new approach to training primary care physicians: a four-year combined internal medicine-family practice residency for seniors. Acad Med 1992;67:88-9.

6. Denton DR, Cobb JH, Webb WA. Practice loca- tions of Texas family practice residency graduates, 1979-1987. Acad Med 1989;64: 400-5.

7. Bergus GR, Levy BT, Randall CS, Dawson JD, Jogerst GJ. Skills that Iowa family physicians desire in a new physician partner. Fam Med 1997;29: 618-24.

8. Osler W. An Alabama student, and other biographical essays. New York: Oxford University Press, 1908.

9. Flexner A. Medical education in the United States and Canada; a report to the Carnegie Foundation for the Advancement of Teaching. New York: The Carnegie Foundation, 1910:xii. [Reprinted, Birmingham, Ala: Classics of Medicine Library, 1990.]

10. Rabinowitz HK, Diamond JJ, Markham FW, Paynter NP. Critical factors for designing programs to increase the supply and retention of rural primary care physicians. JAMA 2001;286:1041-8.

11. Pathman D. Provider retention: Presented at the Rural Medical Educators Conference, National Rural Health Association Annual Meeting, Dallas, May 2001:22-23.

12. Buchbinder SB, Wilson M, Melick CF, Powe NR. Primary care physician job satisfaction and turnover. Am J Manag Care 2001;7:701-13. 